\title{
Brain death diagnosis in adult for potential cadaveric organ donation in Bangladesh
}

\author{
Fatema Ahmed', ASM Areef Ahsan², Mohammad Omar Faruq ${ }^{3}$, Kaniz Fatema ${ }^{4}$, Debasish Kumar Saha ${ }^{5}$, \\ Madhurima Saha ${ }^{6}$, Suraiya Nazneen 7 Md Shah Zaman ${ }^{8}$, Md.Rezaul Karim, Khan Md. Shafikul Alam ${ }^{10}$, \\ Tarikul Hamid ${ }^{11}$
}

\begin{abstract}
Aim: The objectives of this study was (i) To increase knowledge of the epidemiological and clinical features of patients diagnosed with brain death for potential cadaveric organ donation (ii) To determine the compliance of guidelines brain death based on neurological criteria (iii) To analyse process of clinical decision making regarding continuation of life support after brain death diagnosis.

Materials and Method: A prospective observational study was carried out in a 12 bed adult ICU of a tertiary care hospital with neurosurgery services in Bangladesh over a period of 2 years from January 2015 to December2016. All patients admitted during this period were scrutinized for identification of brain death and impending brain death. They were analyzed for causes of brain death, diagnosis of brain death, and the use of ancillary testing. Potential for organ donation was also kept in mind.

Results: During the study period, total 1387 patients were admitted into the study ICU and there were 329 deaths. And out of them 69 were diagnosed as brain death. The main causes of brain death were intracerebral haemorrhage (32/69, $46 \%)$, followed by ischemic stroke (11/69, 16\%), subarachnoid haemorrhage (11/69, 12\%), traumatic brain injury $(8 / 69,12 \%)$ and brain tumor and CNS infection. The diagnosis of brain death was made in 33 (47\%) cases in the first 48 hours and 23 (33\%) cases in 48-96 hours of ICU admission. With the exception of two cases, all study patients had GCS score $\leq 8$ (97\%). Brain death was diagnosed according to American Academy of Neurology (AAN) 2010 guidelines. Only two cases Electroencephalography was done for family request. All life-sustaining measures were withdrawn in 67 (97\%) cases with consent of family.
\end{abstract}

Conclusion: There is no scarcity of brain death cases in our country according to our study. We need to promote and popularize the cadaveric organ transplant along with living donor transplantation.

Key Words: Brain death, Intensive Care Unit, cadaveric transplantation

\section{Introduction:}

The diagnosis of brain death has important medical, ethical and legal implications. Death is defined as "An individual who has sustained either (1) irreversible cessation of circulatory and respiratory functions or (2) irreversible cessation of all functions of the entire brain, including the brain stem (otherwise called Brain Death), is dead." A determination of death must be made in accordance with accepted medical standards.

Brain death is a concept that entered clinical practice when mechanical ventilators made it possible to artificially sustain patients after brain function ceased. Traditionally, a patient was considered alive until the heart stopped, but with the advent of modern life support techniques, the heart can continue to beat even when there is irreversible cessation of brain function.

Brain death is a state of cessation of cerebral function wherein the proximate cause is known and is considered irreversible. The American Academy of Neurology (AAN) has defined brain death with three cardinal signs, cessation of the functions of the brain including the brainstem, coma or unresponsiveness and apnea. ${ }^{2}$ According to the literature, no patients have recovered after a brain death declaration using AAN guidelines.
The concept of brain death was first introduced in United States in 1968 (Ad hoc Committee of the Harvard Medical School to Examine the Definition of Brain Death, 1968) in part to facilitate organ donation. ${ }^{3}$

Studies done elsewhere suggest lack of awareness and misunderstanding on many issues regarding brain death, persistent vegetative state (PVS) and differentiation between severe brain injury versus brain death. ${ }^{4,5}$ At times, the ethical and religious considerations have also been found to affect decisions regarding diagnosis of brain death. ${ }^{6,7,8}$. The concept of brain death was accepted by a majority of scholars and jurists at the Third International Conference of Islamic Jurists in Amman, Jordan, in 1986.9

Brain death declaration has been legalized in Bangladesh in 1999 (No- 5 under "Transplantation of Organ Act, 1999)."10

In many countries, including India, the diagnosis of brain death is made after fulfilling the mandatory criteria and by the apnea testing which is a safe technique for documentation. ${ }^{11}$ In India the deceased donor organ donation rate is only 0.26 per million ${ }^{12}$ while USA at 25.6 per million ${ }^{13}$, and UK at 18.3 per million ${ }^{14}$ are well ahead. 
A systematic review of brain death during pregnancy has concluded that the mother should be supported until the delivery of the fetus and then can be considered for organ donation. ${ }^{15}$

Organs for donation are retrieved from both living donors as well as cadavers. In Bangladesh, however, almost all organ donations come from living donors. ${ }^{16}$ Major organ transplantation is the treatment of choice in many conditions. The fact remains that the demand of organs will always be more than the actual potential organ donors. ${ }^{17}$ Since the latter is almost always 'brain dead patients' maintained on the ventilators, so the concept of 'brain death' among treating physician and general public is central to the success of transplantation. A potential donor is one who is brain-dead with a clearly expressed intent from the family to withdraw life support. ${ }^{18}$

In Bangladesh, it is estimated that only 130 patients (of end stage renal failure requiring kidney transplant) on average can manage live donors to undergo kidney transplant against the annual demand of estimated $5000^{19}$. The limited availability of organs amidst a growing demand emphasizes the need for popularizing cadaveric transplantation worldwide including our country.

1. Fatema Ahmed, Assistant Professor, Dept. of Critical Care Medicine, BIRDEM General Hospital, Dhaka

2. ASM Areef Ahsan, Professor and head, Dept. of Critical Care Medicine, BIRDEM General Hospital, Dhaka

3. Mohammad Omar Faruq, Professor, Dept. of Critical Care Medicine, Ibn Sina Hospital, Dhanmondi, Dhaka

4. Kaniz Fatema, Consultant, Dept. of Critical Care Medicine, BIRDEM General Hospital, Dhaka

5. Debasish Kumar Saha, Registrar, Dept. of Critical Care Medicine, BIRDEM General Hospital, Dhaka

6. Madhurima Saha, Registrar, Dept. of Critical Care Medicine, BIRDEM General Hospital, Dhaka

7. Suraiya Nazneen, Registrar, Dept. of Critical Care Medicine, BIRDEM General Hospital, Dhaka

8. Md Shah Zaman, Consultant. Uttara Crescent Hospital, Dhaka

9. Md. Rezaul Karim, Honorary medical officer. Dept. of Critical Care Medicine, BIRDEM General Hospital, Dhaka

10. Khan Md. Shafikul Alam. Resident medical officer. ICU of Islami bank central Hospital, Dhaka.

11. Tarikul Hamid.Medical officer. Dept. of Critical Care Medicine, BIRDEM General Hospital, Dhaka

\section{Corresponding Author:}

Dr. Fatema Ahmed

MD (Critical Care Medicine), FCPS (Medicine)

Assistant professor, Dept. of Critical Care Medicine

BIRDEM General Hospital, Shahbag, Dhaka-1000, Bangladesh

E-mail: fatema.ahmed77@ymail.com

Cell: +8801822924221

\section{Materials and Method:}

A prospective observational study was carried out in a 12 bed adult ICU of a tertiary care, private hospital with an active neurosurgery department in Bangladesh.

This study aimed to (i) Increase knowledge of the epidemiological and clinical features of patients diagnosed with brain death for potential cadaveric organ donation, (ii) To determine the compliance of guidelines brain death based on neurological criteria, (iii) To analyse process of clinical decisions regarding continuation of life support after brain death diagnosis.

An identification code was given to all cases to assure confidentiality of the data obtained. Ethical clearance was taken from hospital. Individual consent as waived because of anonymous nature of data collection. All adults $>20$ years diagnosed with brain death during the period the study from January 2015 to December 2016 were included in our study.

Brain death was diagnosed in the presence of a severe structural brain lesion, a Glasgow Coma Scale $\left(\mathrm{GCS}^{20}\right)$ of $3 / 15$, and absence of brainstem reflexes in patients who had no significant metabolic abnormalities, or residual effects of sedative drugs. Clinical examination and an apnoea test and ancillary tests ${ }^{21}$ were performed, following AAN guideline ${ }^{2}$ and Bangladesh legislation. ${ }^{10}$ Patient who were suspected to be brain death but apnea test couldn't be done were excluded from the study.

Data collection was done by going through the patient's files after declaration of brain death.

We collected information including age and sex, diagnosis, hospital and ICU length of stay, and severity scores (GCS \& Hunt and Hess scale ${ }^{22}$ ) on admission on a data sheet. The GCS was used for traumatic brain injury, intracerebral haemorrhage and anoxic encephalopathy. The Hunt \& Hess Scale was used on patient of subarachnoid haemorrhage (SAH) in addition to GCS.

SPSS version 21.0 was used for the statistical analysis. Continuous variables were expressed as mean \pm standard deviation (SD). Categorical or qualitative data were expressed as frequency with corresponding percentages. Chi-square was performed where appropriate. We used one-factor ANOVA for comparison when the variables were normally distributed. $P$ value $\leq 0.05$ was considered to be of statistical significance

\section{Results:}

During the study period, total 1387 patient got admitted into the study ICU and there were 329 deaths. And 69 (20\%) out of 329 patients were diagnosed as brain death. Common age of brain dead patients varied between 40 to 60 years $(47 \pm 16.47)$. Majority of the patients were male, 48 (69\%) (Table I). Table II showed breakdown of sources of admission.

Among the study patients in 67 (97\%) cases, the admission Glasgow Coma Scale was $\leq 8 / 15$ (Table III). EEG was done in two cases where "lazarus sign" (Reflex movements in patients with Brain Death) ${ }^{23}$ was positive, another patient was advised cerebral angiography because of family request. 
Bangladesh Crit Care J March 2017; 5 (1): 48-52

Common comorbidities of the patients were HTN $(25,36 \%)$ then DM $(13,18 \%)$ and 4 patients had ESRD (End stage renal disease) and 4 patients had ICSOL (intracranial space occupying lesion). Table IV shows different causes of Brain death. Among them intracerebral Hemorrhage was the most frequent $(46.4 \%)$ cause.

Table $\mathrm{V}$ shows the time of diagnosis of brain death from admission. Majority of cases were diagnosed at 48 hours $(47 \%)$.

Table I: Socio-demographic characteristics of study population

\begin{tabular}{ccc}
\hline Variable & Frequency & Percent \\
\hline Age & & \\
$20-40$ & 22 & 31.9 \\
$41-60$ & 30 & 43.5 \\
$61-80$ & 16 & 23.2 \\
$>80$ & 1 & 1.4 \\
& & \\
Gender & & \\
Male & 48 & 69.6 \\
Female & 21 & 30.4 \\
Total & 69 & 100.0 \\
\hline
\end{tabular}

Table II: Source of Admission

\begin{tabular}{ccc}
\hline Sources & Frequency & Percentage \\
\hline Emergency room & 28 & 40.6 \\
Inpatient unit of & 9 & 13.0 \\
same Hospital & & \\
Inter Hospital ICU & 3 & 4.3 \\
Inter Hospital & 29 & 42.0 \\
Inpatient unit & & 100.0 \\
Total & 69 &
\end{tabular}

Table III: GCS at the Time of admission

\begin{tabular}{ccc}
\hline GCS & Frequency & Percentage \\
\hline $3-5$ & 57 & 82.6 \\
$6-8$ & 10 & 14.5 \\
$>8$ & 2 & 2.9 \\
Total & 69 & 100.0
\end{tabular}

\section{Discussions:}

We diagnosed 69 brain death patients, which comprise of $20 \%$ of our overall deaths in the study hospital with neurosurgery service but no dedicated neurocritical care unit. One study done in Spain comparing ICU with neurosurgery services and ICU without neurosurgery service, showed rate of brain death to be $8 \%$ and $13 \%$ among all deaths respectively. ${ }^{24}$ Another study done in Portugal, showed hospitals with neuro-critical care units having $33 \%$ brain death among total number of deaths. ${ }^{25}$ 
In our study significant admission of patients who developed brain death came from another hospital inpatient unit (42\%) and through emergency services of study hospital (40\%).The rush of out of hospital transfer happened because transferring hospital lacked ICU services.

Our study showed that, the predominant conditions causing brain death were intracerebral hemorrhage $(47 \%)$. This is essentially similar to a study done in Qatar in 2016 which showed the result to be $45.3 \% .^{26}$

Literature review ${ }^{27}$ claimed that major factor associated with SAH are level of consciousness (GCS), age of patient and amount of blood shown in blood in CT scan (Hunt and Hess scale). We have 10 patients of SAH in our study \& those patients had GCS $<8$ and the Hunt and Hess Scale was 4-5 in $80 \%$ of $\mathrm{SAH}$.

In a study done by Escudero $\mathrm{D}$ et $\mathrm{al}^{28}$, the diagnosis of brain death was done exclusively on clinical examination in only 92 patients $(5 \%)$, while at least one ancillary test was used in 1752 patients $(95 \%)$. Diagnosis of brain death was based on the clinical examination as well as apnea test in all cases in our study. This is opposite to the western study \& where ancillary tests are readily available. EEG was done in two cases as patient's family request in our study.

In our study the length of ICU stay was $<48$ hours in $47 \%$ of cases after brain death diagnosis whereas in a study done by Escudero D et $\mathrm{al}^{28}, 50 \%$ of cases had length of stay was $\leq 24$ hours.

In Bangladesh we have legislation for cadaveric organ transplantation in human but cadaveric organ transplantation is still not practised. Schnitzler MA et al, ${ }^{29}$ estimated that a multi-organ donation of six organs provides 55.8 years of life to the various recipients.

In our study (Table VI) GCS on admission was $\leq 5 / 15$ in $82 \%$ of the cases and GCS $\geq 6 / 15$ in $18 \%$ of cases. Brain death was diagnosed in $28(40 \%)$ cases in the first $48 \mathrm{~h}$ who had GCS within 3-5 $(P$ value $=0.003)$. Length of ICU stay depended on severity (GCS) at admission: as severity increased, the length of stay decreased. In the study done by Escudero ${ }^{28}$ showed GCS was $\leq 8 / 15$ in $91 \%$ of the patients admitted and patients deteriorated to brain death (50\% in the first $24 \mathrm{~h})$.

Withdrawal of all types of life-sustaining treatments was performed in 67 (97\%) cases who might be a donor in our study. In a study done by Escudero total $1291(70 \%)$ of the 1844 brain death patients became actual organ donors ${ }^{28}$.

Martin- Lefevre L et $\mathrm{al}^{30}$, emphasized need for regular assessment for brain death to determine likelihood of evolving to brain death. Healthcare professionals should enquire the patient's wishes (living will) regarding organ donation at the time of admission to ICU. This fact might have contributed to the high rates of organ donation in that study.

In our country there is no incentive for quick diagnosis of brain death because there was no practice for organ donation. In contrast, in western countries the diagnosis is much faster to make organ donation possible..$^{30}$ According to one
Bangladeshi study ${ }^{16}$ more than half (57\%) physicians had no knowledge about the organ transplant Act, 1999 of Bangladesh but more than three fourth $(76.4 \%)$ physicians knew about theoretical basis of kidney transplant.

Since the first publication on criteria for brain death diagnosis published 49 years ago $^{31}$, brain death is still not considered equivalent to death by some heath care professional ${ }^{32}$.

In our study all life-sustaining measures were withdrawn in (67) $97 \%$ cases with consent of family within 1-2 days of brain death diagnosis. The reason for that family decision appears to be financial.

\section{Conclusion:}

Our study is a single center study, but we believe the outcome of our study reflect the general scenario of Bangladesh. There are plenty of brain death diagnosed cases in large hospitals of our country. Each of these cases are potential cadaveric donors. We need to promote and popularize cadaveric organ donations to save lives of many of our potential recipients who might get new lives.

\section{Acknowledgement:}

We are grateful to Prof. M.A. Mansur (Professor, dept. of nephrology and Dialysis) for his technical support.

\section{References:}

1. President's Commission for the Study of Ethical Problems in Medicine and Biomedical and behavior Research: Guidelines for the determination of death-Report of the Medical Consultants in the Diagnosis of Death. JAMA 1981 Nov 13; 246:2184-2186

2. Wijdicks EF, Varelas PN, Gronseth GS, Greer DM. American Academy of Neurology. Evidence-based guideline update: Determining brain death in adults: Report of the Quality Standards Subcommittee of the American Academy of Neurology. Neurology. $2010 ; 74: 1911-8$.

3. Ad hoc Committee of the Harvard Medical School to examine the definition of brain death. A definition of irreversible coma. JAMA 1968;205: 337-40

4. Pernick M.S. Brain death in a cultural context: The reconstruction of death 1967-1981. In S. J. Younger, R. M. Arnold, and R. Schapiro (Eds), The definition of death: Contemporary controversies (pp. 3-33). Baltimore: Johns Hopkins University Press.

5. Giacomini M. A change of heart and a change of mind: technology and redefinition of death in 1968. Soc Sci Med. 1997; 44: 1465-82

6. Spoor MT, Sutherland FR. The evolution of the concept of brain death. Am R Coll Physicians Surg Can 1995; 28:30-2.

7. Green M.B, Wikler D. Brain death and personal identity. Philosophy and public affairs. 1980; 9:105-33.

8. Jennet B, Plum F. Persistent vegetative state after brain damage. Lancet 1972; 1: 734-7.

9. Organ transplantation: An Islamic perspective. In: Al Bar MA, edi. Contemporary topics in Islamic medicine. Jeddah: Saudi Arabia Publishing and Distributing House 1995: 147-53.

10. Bangladesh gazette, Bangladesh National Assembly, April,1999. Act No-5, "Transplantation of Human Organs Act, 1999" in Bangladesh 
11. Machado C, Perez J, Scherle C, Areu A, Pando A. Brain death diagnosis and apnea test safety. Ann Indian Acad Neurol. 2009; 12:197-200.

12. Amalorpavanathan J, Shroff S, Karunakaran CE, Castro R. Annual Report from Tamil Nadu Organ Sharing Registry for the year 2013-2014. Available: http://www.tnos.org/pdf/report.pdf .

13. Gómez MP, Arredondo E, Páez G, Manyalich M. International Registry in Organ Donation and Transplantation 2010. Transplant Proc. 2012; 44:1592-7.

14. Johnson RJ, Bradbury LL, Martin K, Neuberger J. UK transplant registry organ donation and transplantation in the UK-the last decade: A report from the UK national transplant registry. Transplantation. 2014; 97(Suppl 1):S1-27.

15. Esmaeilzadeh M, Dictus C, Kayvanpour E, Sedaghat-Hamedani F, Eichbaum M, Hofer $S$ et al. One life ends, another begins: Management of a brain-dead pregnant mother-A systematic reviewBMC Med. 2010; 8:74.

16. Billah MM, Rahman MA, Farzana H, Latif A, Mitra P, Ahmed T, et all Knowledge and Attitude of Bangladeshi Physicians towards Organ Donation and Transplantation. Bangladesh Crit Care J March 2016; 4 (1): 23-27

17. Hauptman PJ, O’Connor KJ. Procurement and allocation of solid organs for transplantation. N Engl J Med 1997; 336:422-31.

18. Wood KE, Becker BN, McCartney J, D'Alessandro AM, Coursin DB. Care of the potential organ donor. $N$ Engl $J$ Med. 2004;351:2730-9.

19. Ali M, Organ transplantation in Bangladesh - Challenges and opportunities, editorial, Ibrahim med. Coll. J. 2012; 6(1): i-ii

20. Jennett B, Bond M. Assessment of outcome after severe brain damage: a practical scale. Lancet 1975; 1: 480-4.

21. Wijdicks EF,.The d iagnosis of brain death. N Engl J Med, 2001; Vol. 344 , No. $16: 1215-21$

22. Hunt WE, Hess RM. Surgical risk as related to time of intervention in the repair of intracranial aneurysms. Journal of Neurosurgery 1968; 28: 14-20.
23. Han S G, Kim G M, K, Lee K H, Chung C S, and Jung K Y. Reflex Movements in Patients with Brain Death: A Prospective Study in A Tertiary Medical Center. J Korean Med Sci. 2006 Jun; 21(3): 588-590.

24. De la Rosa G, Dom nguez-Gil B, Matesanz R, et al. Continuously evaluating performance in deceased donation: The Spanish quality assurance program. American Journal of Transplantation 2012; 12: 2507-13.

25. Escalante JL, Escudero MD, Nolla M, Navarro A and Transplant Working Group of SEMICYUC. Diagnosis of brain death. Multicenter study, Portuguese Journal of Intensive Medicine 1998; 7: 127 .

26. George S, Thomas M, Ibrahim W H, Abdussalam A, Chandra P, Ali H. S. and Raza T. Somatic survival and organ donation among brain-dead patients in the state of Qatar. BMC Neurology, 2016;16:207

27. Suarez JI, Tarr RW, Selman WR. Aneurysmal subarachnoid haemorrhage. New England Journal of Medicine 2006; 354: 387-96.

28. Escudero D, Valentín MO, Escalante JL, Sanmartín A, Perez-Basterrechea $\mathrm{M}$, de Gea $\mathrm{J}$ et al. Intensive care practices in brain death diagnosis and organ donation. Anaesthesia 2015, 70, $1130-1139$

29. Schnitzler MA, Whiting J, Brennan D, et al. The live years saved by a deceased organ donor. American Journal of Transplantation 2005; 5: 2289-96.

30. Martin-Lefevre L, Jacob JP, Pessionne F. Management of organ donation for patients with severe coma due to cerebrovascular stroke. Revue Neurologique 2011; 167: 463-7.

31. A definition of irreversible coma. Report of the Ad Hoc Committee of Harvard Medical School to examine the definition of brain death. JAMA 1968; 205: 85-8.

32. Sheerani M, Urfy MZ, Khealani B, Patel J, Qamarunnisa, Rath S. Brain death: concepts and knowledge amongst health professionals in province of Sindh, Pakistan. Journal of the Pakistan Medical Association 2008; 58: 352-6. 